\title{
Exploring the structural relationships between medical students' motivational regulation, cognitive learning, and academic performance in online learning
}

\author{
Heoncheol Yun', Seon Kim² and Eun-Kyung Chung ${ }^{2}$ \\ ${ }^{1}$ Institute of Educational Research, Chonnam National University, Gwangju and ${ }^{2}$ Department of Medical Education, \\ Chonnam National University Medical School, Hwasun, Korea
}

Purpose: The purpose of this study was to investigate the effect of motivational regulation strategies (MRSs) on cognitive learning and academic performance.

Methods: The participants were a total of 510 pre-medical and medical students. Survey instruments assessed the use of MRSs and cognitive learning strategies. Students' grade point averages were used for academic performance. Structural equation modeling was used to analyze data, using Mplus ver. 7.4 (Muthén \& Muthén, Los Angeles, USA).

Results: Confirming the measurement model validity, the results of structural model indicated the followings: (1) MRSs had a significant impact on cognitive learning, while these strategies negatively affected academic performance; (2) cognitive learning significantly influenced academic performance and mediated the effect of MRSs on academic performance; and (3) only academic levels had a significant effect on cognitive learning.

Conclusion: The findings from this study confirmed that MRSs were highly influential to predicting students' cognitive learning which affects their better learning performance. Thus, instructional design and practice to support learning motivation is needed to promote cognitive learning and training programs to practice the effective methods of using MRSs in learning need to be provided.

Key Words: Motivational regulation, Cognitive learning, Academic performance, Medical students, Online learning

\section{Introduction}

As the coronavirus disease 2019 (COVID-19) had begun to proliferate across South Korea in the early spring of 2020, the Korean Ministry of Education swiftly forced schools and institutions to initiate online education. Medical schools would have transited to online teaching and learning without appropriate preparations during the COVID-19 outbreaks despite the growing attention to online learning used for medical education for the last two decades [1]. By its own nature, online education encourages learners to become selfregulated in learning that they need to be autonomous and proficient learners to initiate, direct, and manage cognitive, metacognitive, and motivational behaviors for their own successful learning experiences [2,3]. That is, online learning environments support students to be highly self-regulated learners for enhancing their cognitive and motivational effort [4]. In other words,
Received: February 9, 2021 • Revised: April 24, 2021 • Accepted: May 3, 2021 Corresponding Author: Eun-Kyung Chung (https://orcid.org/0000-0002-3595-0220) Department of Medical Education, Chonnam National University Medical School, 264 Seoyang-ro, Hwasun-eup, Hwasun 58128, Korea

Tel: +82.61.379.2602 Fax: +82.62.232.9708 email: ekcmedu@chonnam.ac.kr
Korean J Med Educ 2021 Jun; 33(2): 115-124

https://doi.org/10.3946/kjme.2021.193

eISSN: 2005-7288

(C) The Korean Society of Medical Education. All rights reserved. This is an open-access article distributed under the terms of the Creative Commons Attribution Non-Commercial License (http:// creativecommons.org/licenses/by-nc/3.0/), which permits unrestricted non-commercial use, distribution, and reproduction in any medium, provided the original work is properly cited. 
learner motivation has been a crucial factor in effective online learning for pursuing learning goals [1,5]. Also, the regulation of motivation is a critical component of self-regulated learning (SRL) to accomplish academic tasks [6].

Motivational regulation refers to the process in which learners actively monitor, regulate, and sustain their learning motivation with regard to promoting their learning effort and persistence to successfully complete given tasks that they may lose their motivation due to various reasons (e.g., too difficult or boring tasks) [6]. In this way, learners who actively initiate, monitor, and manage their learning motivation can self-regulate their learning process and experience in autonomous ways. Wolters [6] presented the specifics of five motivational regulation strategies (MRSs) along with a motivational regulation process throughout his empirical work. The five different MRSs are interest enhancement, mastery self-talk, performance self-talk, environmental control, and self-consequating. More precisely, Schwinger and Stiensmeier-Pelster [7] specified the motivational regulation process of how the learner perceives low motivation, determines a need of higher motivation, utilizes MRSs to increase motivation, and achieves desired learning goals. The original MRSs of Wolters [6] were extended into eight MRSs [8]: enhancement of situational interest, enhancement of personal significance, mastery self-talk, performance approach selftalk, performance avoidance self-talk, self-consequating, proximal goal setting, and environmental control.

As previously mentioned, highly motivated learners tend to be efficient in self-regulating their own learning process, promoting to use cognitive learning while they actively regulate their motivation [9]. Cognitive learning refers to the effective ways in which learners process basic or complex information from texts and instructions including rehearsal, elaboration, organization, and critical thinking [2,4]. Hence, motivational regulation is crucial in SRL and in turn cognitive learning in SRL can be facilitated by using the different sets of MRSs. The notion that motivational regulation can be predictive of using cognitive learning and learning achievement appears to be consistent with findings from prior research. Pelaccia and Viau [10] argued that motivated medical students can use learning strategies in more effective ways to overcome learning obstacles and accomplish better academic achievement than less motivated students. Also, motivational beliefs of medical students played an important role in contributing to their academic achievement via achievement emotions [11]. Previous research showed that individuals' cognitive learning differences could have an impact on learners' interaction in web-based learning [12] and cognitive and motivational beliefs were crucial factors to predict the use of metacognitive learning strategies and performance in online learning [13].

Regardless of medical education, motivation has been perceived as an important factor in enhancing learning. In addition, educational researchers have rigorously focused on learners' motivational and cognitive beliefs and behaviors for understanding effective learning process and improving academic performance. However, there has been little research to date to examine the effects of using MRSs on cognitive learning and learning performance among medical students in online learning environments. Thus, this study developed research questions as followings: (1) Are there any structural relationships between the use of MRSs, cognitive learning, and academic achievement among medical students in online learning? (2) Does cognitive learning mediate the relation between the use of MRSs and academic achievement? and (3) Do gender and academic levels have impacts on using MRSs and cognitive learning strategies (CLS)? 


\section{Methods}

\section{Participants}

An online survey was conducted in July 2020 after the transition to a partial online education with the approval of the Institutional Review Board of Chonnam National University (IRB no., 1040198-200701-HR-072-02). Using a convenience sampling, data were collected from 184 pre-medical students and 359 medical students enrolled at the medical school of a public research university in Korea. More specifically, this medical school has a 6-year curriculum which is divided into three parts: premedical course, preclinical phase, and clinical phase. Of the entire participants, 33 cases were excluded for the final data analysis because of thoroughly incomplete and inconsistent responses to the self-administered survey. Hence, a total number of 510 participants consisted of 179 female (35.1\%) and 331 male (64.9\%) students.
Regarding academic levels, there were 90 (17.6\%) firstyear and 86 (16.9\%) second-year pre-medical students, and $118(23.1 \%)$ first-year, 109 (21.4\%) second-year, and $107(21.0 \%)$ third-year medical students. The mean age of the participants was 21.99 (standard deviation $[\mathrm{SD}]=2.33)$.

\section{Measures}

\section{1) Motivational regulation}

To assess medical students' motivational regulation, this study accordingly modified based on the research contexts and used the eight MRS questionnaire extended by Schwinger et al. [8]. This instrument was validated by empirical evidence of confirmatory factor analysis and correlation analysis using college student subjects [8]. The MRS questionnaire consists of 30 items with four constructs: interest enhancement, goal orientation, behavioral reinforcement, and environmental control. Table 1 presents the descriptions of each MRS [8]. Each survey item was responded using a 5-point Likert scale

\begin{tabular}{|c|c|c|}
\hline Construct & MRS (no. of items) & Description (sample item) \\
\hline \multirow[t]{2}{*}{ Interest enhancement } & $\begin{array}{l}\text { 1. Enhancement of } \\
\text { situational interest (5) }\end{array}$ & $\begin{array}{l}\text { Turning a relatively tedious task into a more fascinating one through imaginative } \\
\text { modification. (I make learning more pleasant for me by trying to arrange it } \\
\text { playfully.l }\end{array}$ \\
\hline & $\begin{array}{l}\text { 2. Enhancement of personal } \\
\text { significance (3) }\end{array}$ & $\begin{array}{l}\text { Establishing a connection between the task and one's own personal interests } \\
\text { and preferences. II look for connections between the tasks and my life as such.) }\end{array}$ \\
\hline \multirow[t]{3}{*}{ Goal orientation } & 3. Mastery self-talk (4) & $\begin{array}{l}\text { Highlighting the goal to enlarge one's competence and master challenging tasks. } \\
\text { (I persuade myself to work intensely for the sake of learning.) }\end{array}$ \\
\hline & $\begin{array}{l}\text { 4. Performance approach } \\
\text { self-talk (5) }\end{array}$ & $\begin{array}{l}\text { Earning a higher exam grade than one's classmates. II call my attention to the } \\
\text { fact of how important it is to obtain good grades.) }\end{array}$ \\
\hline & $\begin{array}{l}\text { 5. Performance avoidance } \\
\text { self-talk (3) }\end{array}$ & $\begin{array}{l}\text { Avoiding others who make fun of one's poor performance.II tell myself that } \\
\text { I have to push me more if I do not want to make a fool of myself. }\end{array}$ \\
\hline \multirow[t]{2}{*}{ Behavioral reinforcement } & 6. Self-consequating (4) & $\begin{array}{l}\text { Self-administered gratification for achieving a certain goal. II put the prospect } \\
\text { of any reward to myself in case I finish work.) }\end{array}$ \\
\hline & 7. Proximal goal setting (3) & $\begin{array}{l}\text { Dividing learning materials into small and manageable pieces to experience success } \\
\text { more quickly and frequently. II break down the work load in small segments } \\
\text { so I get the feeling that I can handle it more easily.I }\end{array}$ \\
\hline Environmental control & 8. Environmental control (3) & $\begin{array}{l}\text { Intentionally eliminating possible distractions. (I make sure that distractions occur } \\
\text { as seldom as possible.) }\end{array}$ \\
\hline
\end{tabular}

MRS: Motivational regulation strategies. 
with a response range from 1="strongly disagree" to 5="strongly agree". The higher scores of MRSs, the more actively students used MRSs.

\section{2) Cognitive learning}

We used the CLS under the Motivated Strategies for Learning Questionnaire (MSLQ) to measure medical students' cognitive learning [14]. Using college students, several learning strategies in MSLQ including CLSs were empirically validated through a couple of confirmatory factor analyses [14]. CLSs include 19 survey items with two strategies: a surface level strategy and deep processing strategy. The surface level strategy includes rehearsal and the deep processing strategies include elaboration, organization, and critical thinking. Table 2 indicates the specifics of CLSs [14]. Like MRSs, a 5-point Likert scale was used for each survey item of CLSs with a range from 1="strongly disagree" to $5=$ "strongly agree". The higher values of CLSs, the more rigorously students applied CLSs in learning.

\section{3) Academic performance}

In this study, academic performance was conceptualized by students' grade point averages (GPAs) in the current semester. The overall mean of students' GPAs was $3.60(\mathrm{SD}=0.60)$ with a possible range from 4.50 to 1.00 .

\section{Data analysis procedures}

This study used the IBM SPSS ver. 22.0 (IBM Corp., Armonk, USA) to compute descriptive statistics including means, SDs, skewness, kurtosis, Pearson's reliability, and correlations and Mplus ver. 7.4 (Muthén \& Muthén, Los Angeles, USA) to conduct structural equation modeling (SEM) using second-order factor analysis with two step approaches: a measurement model and structural model. The estimation method used for SEM was maximum likelihood parameter estimates. Prior to analyzing the descriptive statistics of observed variables in a measurement model of SEM, we conducted a preliminary analysis for the validation of a meas-

Table 2. Descriptions of Cognitive Learning Strategies

\begin{tabular}{ll}
\hline CLS (no. of items) & Description (sample item) \\
\hline $\begin{array}{l}\text { Surface level strategy } \\
\text { Rehearsal (4) }\end{array}$ & $\begin{array}{c}\text { Involve review, repetition, recitation, reading aloud and highlighting, or underlining to facilitate the attention, } \\
\text { coding, and retention of information at superficial memory levels. (When I study for this class, I practice } \\
\text { saying the material to myself over and over.) }\end{array}$ \\
\begin{tabular}{|l} 
Deep processing strategies \\
Elaboration (6)
\end{tabular} & $\begin{array}{l}\text { Focused on building connections between different learning content by summarizing, creating analogies, } \\
\text { generative note-taking, explaining ideas and asking and answering questions. Classified as an } \\
\text { intermediate-level strategy as it facilitates commitment to long-term memory. II try to relate ideas in } \\
\text { this subject to those in other courses whenever possible). } \\
\text { Refers to further processing of information including the selectionof the main interrelated ideas and organization } \\
\text { of them into different categories by outlining and using a variety of specific techniques such as modification } \\
\text { of information and restructuring of knowledge through diagrams, classifications or comparisons. IWhen } \\
\text { I study for this course, I go through the readings and my class notes and try to find the most important } \\
\text { ideas.) } \\
\text { Establishes relationships between prior and new knowledge, leading to the ability to solve problems, make } \\
\text { decisions and evaluations, and develop argumentative and reflective capabilities by thinking critically and } \\
\text { making regressions and inferences. II often find myself questioning things I hear or read in this course } \\
\text { to decide if I find them convincing.) }\end{array}$ \\
\hline Critical thinking (5)
\end{tabular}

CLS: Cognitive learning strategies. 
urement model. Regarding the initial measurement model with the measures of motivational regulation and cognitive learning, we used the criteria for factor loadings of observed variables (measured items), reliability of constructs, and measurement model validity. A threshold for factor loadings should be at least greater than 0.50 and ideally greater than 0.70 [15]. Sufficient consistency reliability of a construct should be higher than 0.70 and reliability higher than 0.60 would be considered acceptable [16]. For measurement model validity, we used model-fit indices Mplus (Muthén \& Muthén) yields such as $\chi^{2}$ statistics, comparative fit index (CFI), Tucker-Lewis index (TLI), root mean square error of approximation (RMSEA), and standardized root mean square residual (SRMR). The $\chi^{2}$ statistics vary due to sample sizes and tend to be significant as a discrepancy between the observed and estimated covariance matrices is large [17]. $\mathrm{Hu}$ and Bentler [18] suggested the following criteria: A reasonable/acceptable model-fit cutoff for CFI and TLI should be greater than 0.90. RMSEA less than 0.05 is considered as a good fit and between 0.05 and 0.08 as a fair fit. SRMR less than 0.08 can be a good fit.

\section{Results}

\section{Descriptive statistics, reliability, and cor- relations}

The descriptive statistics of variables used in SEM with a revised model including means, SDs, skewness and kurtosis were computed, presented in Table 3. Regarding MRSs, students showed the highest score in the goal orientation strategy (mean $\pm \mathrm{SD}, 3.59 \pm 0.65$ ), followed by the behavioral reinforcement strategy (3.55 \pm 0.68$)$ and environmental control (3.40 \pm 0.73$)$. Students the least used the interest enhancement strategy of MRSs to regulate their learning motivation (3.23 \pm 0.80$)$. In light of using CLSs, students the most actively used the elaboration strategy $(3.84 \pm 0.65)$ in learning, followed by the rehearsal $(3.77 \pm 0.69)$ and organization strategy $(3.76 \pm 0.69)$. While the critical thinking strategy was labeled as the least used strategy among CLSs (3.23 \pm 0.80$)$. All variables were negatively skewed and positively peaked except for the rehearsal strategy. Using Cronbach's $\alpha$, internal reliability coefficients of variables were at sufficiently high or

Table 3. Descriptive Statistics of Variables $(n=510)$

\begin{tabular}{|c|c|c|c|c|}
\hline Variable & Mean \pm SD & Skewness & Kurtosis & Cronbach's \\
\hline 1. Interest enhancement & $3.23 \pm 0.80$ & -0.13 & 0.64 & 0.83 \\
\hline 2. Goal orientation & $3.59 \pm 0.65$ & -0.34 & 0.36 & 0.78 \\
\hline 3. Behavioral reinforcement & $3.55 \pm 0.68$ & -0.47 & 0.59 & 0.73 \\
\hline 4. Environmental control & $3.40 \pm 0.73$ & -0.26 & 0.58 & 0.69 \\
\hline 5. Rehearsal & $3.77 \pm 0.69$ & -0.42 & -0.02 & 0.64 \\
\hline 6. Elaboration & $3.84 \pm 0.65$ & -0.29 & 0.44 & 0.75 \\
\hline 7. Organization & $3.76 \pm 0.69$ & -0.45 & 1.08 & 0.74 \\
\hline 8. Critical thinking & $3.51 \pm 0.71$ & -0.37 & 0.40 & 0.69 \\
\hline 9. Academic performance & $3.60 \pm 0.60$ & -0.75 & 0.54 & - \\
\hline 10. Academic levels ${ }^{\text {al }}$ & $3.11 \pm 1.38$ & -0.13 & -1.21 & - \\
\hline 11. Gender ${ }^{b l}$ & $0.65 \pm 0.48$ & -0.63 & -1.61 & - \\
\hline
\end{tabular}

SD: Standard deviation.

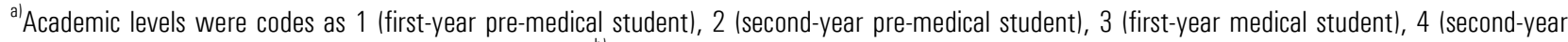
medical student), and 5 (third-year medical student). ${ }^{\text {bl }}$ Gender was coded as 0 (female) and 1 (male). 
acceptable levels with a range from 0.64 to 0.83 .

Using Pearson's coefficients, Table 4 shows the analysis of correlations among variables. MRSs (interest enhancement, goal orientation, behavioral reinforcement, and environmental control) were positively correlated with CLSs (rehearsal, elaboration, organization, and critical thinking) at the significance level of $0.01 \quad(0.36 \leq \mathrm{r} \leq 0.60)$. While MRSs were not significantly correlated with academic performance, academic levels, and gender. However, CLSs including rehearsal, elaboration, and organization were positively correlated with academic performance $(0.12 \leq \mathrm{r} \leq 0.17$, $\mathrm{p}\langle 0.01)$ and negatively correlated with academic levels $(\mathrm{r}=-0.21, \mathrm{p}<0.01 ; \mathrm{r}=-0.11, \mathrm{p}\langle 0.05 ; \mathrm{r}=-0.11, \mathrm{p}<0.05$, respectively). Only, the critical thinking strategy of CLS was positively correlated with gender $(\mathrm{r}=0.11, \mathrm{p}<0.05)$.

\section{Structural equation modeling}

\section{1) Measurement model}

Throughout the preliminary analysis, changes were made for a revised measurement model. We assessed the validity of the revised measurement model. According to

\begin{tabular}{|c|c|c|c|c|c|c|c|c|c|c|c|}
\hline Variable & 1 & 2 & 3 & 4 & 5 & 6 & 7 & 8 & 9 & 10 & 11 \\
\hline 1 & 1 & & & & & & & & & & \\
\hline 2 & $0.46^{* *}$ & 1 & & & & & & & & & \\
\hline 3 & $0.59^{* *}$ & $0.51^{* *}$ & 1 & & & & & & & & \\
\hline 4 & $0.58^{* *}$ & $0.49^{* *}$ & $0.59^{* *}$ & 1 & & & & & & & \\
\hline 5 & $0.44^{* *}$ & $0.51^{* *}$ & $0.48^{* *}$ & $0.36^{* *}$ & 1 & & & & & & \\
\hline 6 & $0.47^{* *}$ & $0.53^{* *}$ & $0.47^{* *}$ & $0.38^{* *}$ & $0.62^{* *}$ & 1 & & & & & \\
\hline 7 & $0.41^{* *}$ & $0.52^{* *}$ & $0.53^{* *}$ & $0.41^{* *}$ & $0.63^{* *}$ & $0.70^{* *}$ & 1 & & & & \\
\hline 8 & $0.60^{* *}$ & $0.48^{* *}$ & $0.47^{* *}$ & $0.43^{* *}$ & $0.51^{* *}$ & $0.60^{* *}$ & $0.49^{* *}$ & 1 & & & \\
\hline 9 & -0.01 & 0.07 & 0.01 & -0.04 & $0.12^{* *}$ & $0.16^{* *}$ & $0.17^{* *}$ & 0.01 & 1 & & \\
\hline 10 & 0.01 & 0.04 & -0.01 & 0.06 & $-0.21^{* *}$ & $-0.11^{*}$ & $-0.11^{*}$ & -0.02 & $-0.18^{* *}$ & 1 & \\
\hline 11 & 0.03 & -0.02 & -0.04 & 0.01 & 0.03 & 0.04 & 0.02 & $0.11^{*}$ & $-0.22^{* *}$ & -0.02 & 1 \\
\hline
\end{tabular}

Variables are 1 (interest enhancement), 2 (goal orientation), 3 (behavioral reinforcement, 4 (environmental controll, 5 (rehearsal), 6 (elaboration), 7 (organization), 8 (critical thinking), 9 (academic performance), 10 (academic levels, and 11 (gender).

${ }^{*} p<0.05 .{ }^{* *} p<0.01$.

Fig. 1. Path Standardized Coefficients for Structural Model

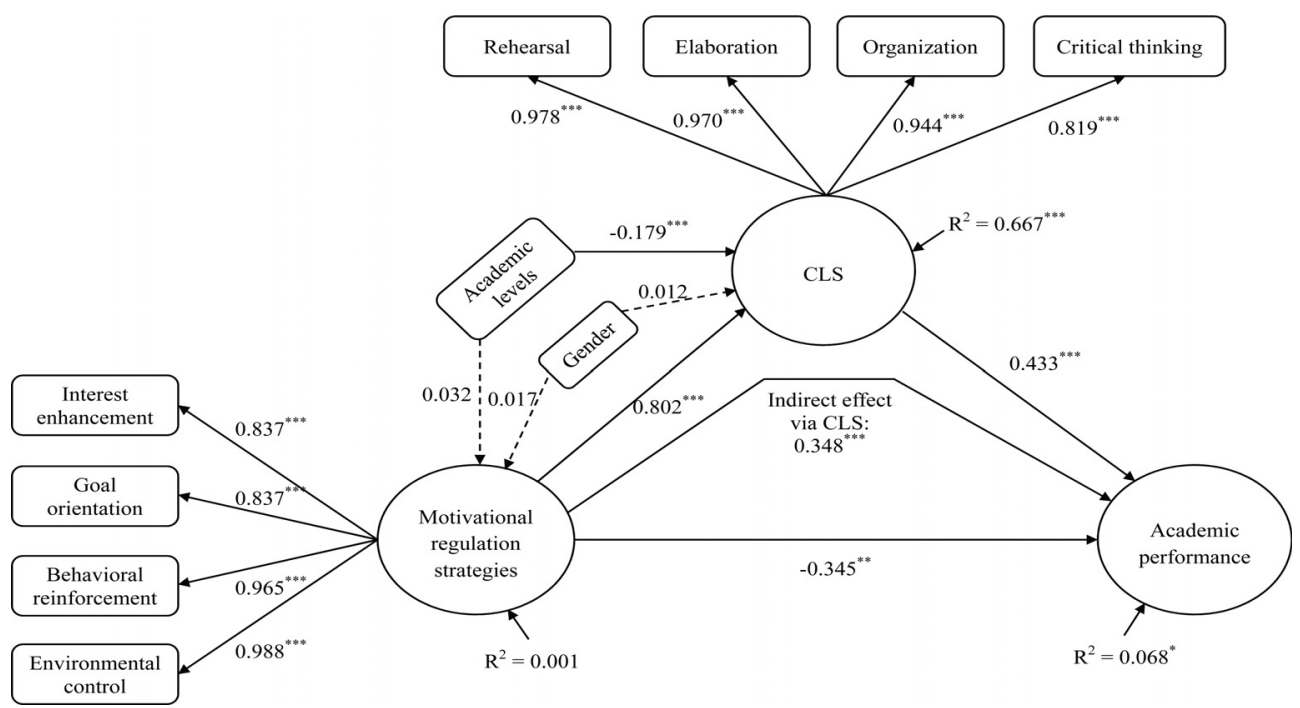

CLS: Cognitive learning strategies. ${ }^{*} p<0.05 .{ }^{* *} p<0.01 .{ }^{* *} p<0.001$. 
the criteria of model fit statistics Mplus (Muthén \& Muthén) indicates, the revised model was identified to fit appropriately to the data $\left(\chi^{2}[103, \mathrm{n}=510]=639.814\right.$, $\mathrm{p}<0.001 ;$ CFI $=0.929 ;$ TLI $=0.919 ; \quad$ RMSEA $=0.043$ [90\% confidence interval, 0.038-0.048]; SRMR=0.055). Factor loadings of variables under MRS and CLS (Fig. 1) were sufficiently high with a range from 0.819 to 0.988 at the significance level of 0.001 .

\section{2) Structural model}

Confirming the measurement model validity, we checked the validity of structural model, designed for this study. We confirmed the structural model adequately fit to the data, based on the results of model fit indices $\left(\chi^{2}[111, \mathrm{n}=510]=809.561, \mathrm{p}<0.001 ; \mathrm{CFI}=0.916 ; \mathrm{TLI}=\right.$ 0.905; RMSEA $=0.044$ [90\% confidence interval, 0.0390.048]; SRMR=0.054). To test the hypothesized structural relationships between MRS, CLS, and academic performance, Fig. 1 displays the path standardized coefficients from SEM. First, MRS is strongly influential to $\operatorname{CLS}(\beta=0.802, \mathrm{p}<0.001)$. That is, the more frequently students use MRSs, the more rigorously student tend to use CLSs. Likewise, CLS has significantly a strong impact on academic performance $(\beta=0.433, \mathrm{p}<0.001)$. If they use CLS more actively in learning, they may earn better GPAs. However, the use of MRSs has a negative influence on academic performance $(\beta=-0.345, \mathrm{p}<0.01)$. Interestingly, the result of model indirect showed that MRS indirectly affected academic performance via CLS ( $\beta=0.348, \mathrm{p}<0.001)$. Hence, using MRSs could indirectly affect their academic performance through using CLSs. In other words, CLS may mediate the relationship between MRS and academic performance. Regarding the effects of academic levels and gender on MRS and CLS, only academic levels negatively affected the use of CLSs in learning $(\beta=-0.179, \mathrm{p}<0.001)$. That is, the lower academic levels students are at, the more likely they tend to use CLSs. Approximately $6.8 \%$ of variance in academic performance is explained by MRS and CLS. Variables including MRS, academic levels, and gender account for $66.7 \%$ of variance in CLS.

\section{Discussion}

In this study, we examined the effect of MRS on cognitive learning and academic performance and the mediating effect of CLS on the relationship between MRS and academic performance among pre-medical and medical students in online learning. Additionally, we assessed whether there were significant differences in using MRSs and CLSs based on students' academic levels and gender. The findings from the results of this study are addressed as followings for providing empirical evidence in relation to using students' motivational regulation enhancing cognitive learning efforts that led to improved academic performance while online learning during the pandemic.

First, this study found that MRSs were significantly associated with cognitive learning which appears to lead to better learning achievement in students' online learning experience. According to predicting the positive relationship between MRSs and CLSs, we found how the specific sets of MRSs can be used for differently using CLSs. The correlations analysis showed that the interest enhancement and environmental control MRSs were strongly related to the levels of the critical thinking strategy in cognitive learning. Also, it confirmed that the goal orientation MRS was highly associated with the more use of the elaboration strategy, and the behavioral reinforcement MRS was connected to promoting the use the organization strategy. Hence, the use of different MRS sets appears to facilitate cognitive learning by using CLSs in different manners, which can be consistent with findings from previous research [4]. More specifically, a 
well-developed interest of the learner, who selfregulates learning, supports for active participation in such a problem-solving task through a critical thinking learning process $[19,20]$. Importantly, the goal orientation MRSs were significant predictors to predict students' learning engagement in completing learning tasks [21]. Thus, the effective use of different MRSs is crucial to students so as to enhance the appropriate use of CLSs for supporting cognitive learning in online learning environments.

Second, this study found that there was a mediation effect of cognitive learning on the relationship between MRS and students' academic performance although MRS had directly a negative influence on academic performance. According to the motivational regulation model [7], MRSs have inherently direct effects on learning efforts or consistency to complete learning tasks, but not on learning achievement [6,8]. As confirming this hypothesis, this study replicated the negatively indirect relationship between MRS and achievement like prior research $[7,8]$. That is, MRSs indirectly affected students' academic performance through cognitive learning. On the other hand, we also confirmed that using CLSs was directly associated with academic performance. Especially, students would likely achieve better learning outcomes when they more frequently used the rehearsal, elaboration, and organization strategies for promoting cognitive learning. Likewise, self-regulation including cognitive learning efforts was found to be significantly related to higher levels of learning engagement [22]. Confirming the motivational regulation process, this study presented that motivational regulation is a critical component in selfregulation by supporting cognitive learning efforts which could be connected to better learning achievement.

Last, we found that students' academic levels as an individual factor were a significant factor in cognitive learning. Contextual factors (e.g., task characteristics, learning settings, and so forth) and individual factors (e.g., prior knowledge, self-esteem, intelligence, and so forth) were essential factors in the motivational regulation model [7]. In this study, students at lower academic levels tended to use more actively CLS (e.g., rehearsal, elaboration, organization, and critical thinking). Hence, students at lower academic levels could be assumed to use more actively the CLS to achieve greater learning outcomes, compared to those at higher academic levels.

In conclusion, we noted that supporting pre-medical and medical students' motivational regulation and cognitive learning efforts is crucial in online learning under such struggling circumstances like the pandemic. Also, the findings from this study suggest that considering the motivational regulation process with contextual and individual factors, educators and instructional designers need to understand the various facets of using MRSs and CLSs by diverse learners. Empirical evidence from this study can provide significant insight to researchers, instructors, and educational practitioners in specifically organizing motivational support strategies and customizing instructional designs for enhancing meaningful learning experience to students in medical education. Of course, MRSs [7,8] and CLSs [14] need to be accentuated in designing online teaching and learning. Crucially, precedent motivational theories such as ARCS-V (attention, relevance, confidence, satisfaction ${ }^{-}$volition) model [23], self-determination theory [24], expectancyvalue theory [25], and control-value theory [26] can be applied to affect students' learning experience for optimizing their motivation and engagement. Given the current learning environments in medical education including online learning and traditional face-to-face learning, we need to focus on integrating the pivotal elements of these underlying motivation theories for 
designing instructions and supporting students who use MRSs in various manners. Moreover, future researchers may utilize the results and findings of this study as resources to provide effective learning contents and learning experience for a wide range of learning groups in medical education.

\section{ORCID:}

Heoncheol Yun: https://orcid.org/0000-0002-0508-0631;

Seon Kim: https://orcid.org/0000-0001-5551-2300;

Eun-Kyung Chung: https://orcid.org/0000-0002-3595-0220

Acknowledgements: None.

Funding: None.

Conflicts of interest: The authors have no conflicts of interest to declare.

Author contributions: Designing this work and drafting this article: HY; conducting data collection and data analysis: SK; and interpreting analysis results and critically revising for the final version of this article to be published: EKC.

\section{References}

1. Pei L, Wu H. Does online learning work better than offline learning in undergraduate medical education?: a systematic review and meta-analysis. Med Educ Online. 2019;24(1):1666538.

2. Pintrich PR, De Groot EV. Motivational and selfregulated learning components of classroom academic performance. J Educ Psychol. 1990;82(1):33-40.

3. Zimmerman BJ. Becoming a self-regulated learner: an overview. Theory Pract. 2002;41(2):64-70.

4. Park S, Yun H. Relationships between motivational strategies and cognitive learning in distance education courses. Distance Educ. 2017;38(3):302-320.
5. Lim DH. Cross cultural differences in online learning motivation. Educ Media Int. 2004;41(2):163-175.

6. Wolters CA. Regulation of motivation: evaluating an underemphasized aspect of self-regulated learning. Educ Psychol. 2003;38(4):189-205.

7. Schwinger M, Stiensmeier-Pelster J. Effects of motivational regulation on effort and achievement: a mediation model. Int J Educ Res. 2012;56:35-47.

8. Schwinger M, Steinmayr R, Spinath B. How do motivational regulation strategies affect achievement: mediated by effort management and moderated by intelligence. Learn Individ Differ. 2009;19(4):621-627.

9. Niemczyk M. Self-regulation and motivation strategies. In: Seel NM, ed. Encyclopedia of the Sciences of Learning. New York, USA: Springer; 2012:3019-3021.

10. Pelaccia T, Viau R. Motivation in medical education. Med Teach. 2017;39(2):136-140.

11. Artino AR, La Rochelle JS, Durning SJ. Second-year medical students' motivational beliefs, emotions, and achievement. Med Educ. 2010;44(12):1203-1212.

12. Chen LH. Web-based learning programs: use by learners with various cognitive styles. Comput Educ. 2010;54(4): 1028-1035.

13. Chen $\mathrm{CH}, \mathrm{Wu}$ IC. The interplay between cognitive and motivational variables in a supportive online learning system for secondary physical education. Comput Educ. 2012;58(1):542-550.

14. Pintrich PR, Smith DA, Garcia T, McKeachie WJ. Reliability and predictive validity of the Motivated Strategies for Learning Questionnaire (MSLQ). Educ Psychol Meas. 1993;53(3):801-813.

15. Hair JF, Black WC, Babin BJ, Anderson RE. Multivariate data analysis. 7th ed. London, UK: Pearson; 2013.

16. Field A. Discovering statistics using SPSS. 3rd ed. London, UK: SAGE; 2009.

17. Kline RB. Principles and practice of structural equation modeling. 4th ed. New York, USA: The Guilford Press; 
2016.

18. Hu LT, Bentler PM. Cutoff criteria for fit indexes in covariance structure analysis: conventional criteria versus new alternatives. Struct Equ Model. 1999;6(1):1-55.

19. Renninger KA. Interest and identity development in instruction: an inductive model. Educ Psychol. 2009; 44(2): 105-118.

20. Hidi S, Renninger KA. The four-phase model of interest development. Educ Psychol. 2006;41(2):111-127.

21. Yun H, Park S. Building a structural model of motivational regulation and learning engagement for undergraduate and graduate students in higher education. Stud High Educ. 2020;45(2):271-285.

22. Sun JC, Rueda R. Situational interest, computer selfefficacy and self-regulation: their impact on student engagement in distance education. Br J Educ Technol. 2012;43(2):191-204.

23. Keller JM. Motivational design for learning and performance: the ARCS model approach. New York, USA: Springer; 2010.

24. Ryan RM, Deci EL. Self-determination theory: basic psychological needs in motivation, development, and wellness. New York, USA: The Guilford Press; 2017.

25. Wigfield A, Eccles JS. Expectancy-value theory of achievement motivation. Contemp Educ Psychol. 2000; 25(1):68-81.

26. Pekrun R. The control-value theory of achievement emotions: assumptions, corollaries, and implications for educational research and practice. Educ Psychol Rev. 2006; 18(4):315-341. 